\title{
Optimal Allocation of SVC for Enhancement of Voltage Stability limit and Minimization of Transmission losses in Power System using Particle Swarm Optimization
}

\section{Radha Verma ${ }^{\# 1}$, Shuchi Shah ${ }^{\# 2}$,Neha Kothari ${ }^{\# 3}$}

\#1 M. Tech Scholar, Mandsaur Institute of Technology Mandsaur (M.P.), India , +91-9691263700 and \#2 Asst. Prof., Department of Electrical Engineering, Mandsaur Institute of Technology Mandsaur (M.P.), India, +91-9098290725

\#3 Asst. Prof., Department of Electrical Engineering, Shri Vaishnav Vidyapeeth Vishwavidyalaya Indore (M.P.),India,+91-9926071715

\begin{abstract}
Voltage stability is a crucial issue in power systems under variable loaded condition. In the present scheme of restructuring the system, this problem becomes even more serious. To solve the problem, we integrate reactive power compensation concept by Static Var Compensator (SVC). We derive an algorithm for steady state power flow control and to overcome with the major problem of voltage instability, voltage collapse \& black out in power system by using FACTS Devices at appropriate place. This paper shows the application of particle swarm optimization (PSO) for optimal allocation of SVC to improve voltage stability limit and to minimize the transmission line losses considering cost function for entire power system planning. The proposed approach is tested on IEEE 14 bus system. Finallythe result shows the enhancement of voltage stability limit and minimization of transmission losses in the power system at different loading.
\end{abstract}

Key words:Voltage Stability, loadability, SVC, PSO.

Corresponding Author:Neha Kothari

\section{INTRODUCTION}

At the present time, power systems are forced to operate at almost full capacity.More and more often, generation patterns result in heavy flows that tend to incur greaterlosses as well as threatening stability and security of the system. This ultimately createsundesirably increased risk of power outages of different levels of severity. For thisreason, there is a general consensus that the power grid has to be reinforced, to make itsmart and aware, fault tolerant and self-healing, and dynamically and staticallycontrollable.

A traditional alternative to reinforce the power network consists of upgrading the electrical transmission system infrastructure through the addition of new transmission lines, substations, and associated equipment. However, the process to permit, site, and construct new transmission lines has become difficult, expensive, time consuming, and many times even controversial.

The utilization of the existing power system can be improved through theapplication of advanced power electronics technologies. Flexible AC TransmissionSystems (FACTS) 
provide technical solutions to address the new operating challengesbeing presented today. Devices, such as a STATCOM, SVC, SSSC, and UPFC, can beconnected in series or shunt (or a combination of the two) to achieve numerous controlfunctions, including voltage regulation, power flow control, and system damping. In this way, the system performance can be considerably improved by controlling the powerflows without generation rescheduling or topological changes. Furthermore, the thermallimits are not violated, losses are minimized, and the stability margin is increased.

The Optimal Power Flow (OPF) has been widely used for both the operation and planning of a power system. The main task is to adjust some control variables in a power system, so that the best operating point can be achieved. In the past two decades, the problem of optimal power flow (OPF) has received much attention. "OPF has been applied to regulate generator active power outputs and voltages, shunt capacitors/reactors, transformer tap settings and other controllable variables to minimize the fuel cost, network active power loss, while keeping the load bus voltages, generators reactive power outputs, network power flows and all other state variables in the power system in their operational and secure limits".

Voltage stability analysis is essential for a secure operation of the power system. A lot of work has been investigated to improve voltage stability. Prevention of the system from voltage collapse \& voltage instability can be done by using FACTS devices. There are various papers that investigate the enhancement of voltage stability limit using FACTS devices.

Kamarposhti and Lesani [1] presented the Effects of various FACTS devices (SVC, STATCOM, SSSC and TCSC) on loading capability and voltage stability of the system using maximum loading point (MLP) index concept of line loadability. Comparison between SVC, STATCOM, TCSC and UPFC for improving the stability of the system by means of reactive power limit concept has been carried out in [2]. Hiyamatet al. [5] have developed fuzzy logic based control scheme for FACTS devices like high speed phase shifter, braking resistor, TCSC \& SVC, to improve the stability of the entire power system. This scheme also shows the simulation results for various FACTS devices.

Shankaralingappa C.B. et al. [3] discussed the optimum required rating of series \& shunt FACTS controllers for enhancementof line loading capability and hence the voltage stability improvement in long Extra High Voltage AC (EHVAC) Transmission lines. The voltage stability of a power system with STATCOM \& OLT's is using PV curves and time-domain simulations are reported in [4]. It has been demonstrated that PV curve simulation can be evaluated by the time-domain simulation. The Margin of Stability is also being evaluated by the PV curve simulation. In [11], the simulation of UPFC is performedfor the enhancement of voltage control in the power system by compensating the transmission line and the result of simulation shows the efficiency of UPFC for controlling of active and reactive power flow in the transmission line.

Salim Haddad et al. [6] describes the theory and simulation of UPFC used for control of voltage in the disturbed power systems using MATLAB. Wanget al. [12], demonstrated the multiple control functions of a UPFC and concludes that the conflict between controlling of series and shunt part of UPFC connected by common capacitor internally is responsible for its analytical results. H. Chenet al. [13] briefly discussed the coordinated excitation \& UPFC control for enhancement of power system stability \& voltage stability margin. Also, by using bifurcation analysis the impact of excitation controller on voltage stability is studied. Shah et 
al. [7] have discussed the static voltage stability of power system with the STATCOM \& SVC. The performance is tested on IEEE-14 bus system with large-scale PV integration, STATCOM \& SVC. The topology\& power flow distribution is affected by incorporating TCSC. To minimize the power system load curtailment by incorporating TCSC into voltage stability constrained optimal power flow (OPF) algorithm by evaluating the reliability measures of composite security-based power system has been proposed by Huang and Nair $[8]$.

Lee et al. [9] discussed that by using Heuristic method one can easily, optimally \& efficiently determine the proper location and size of the FACTS devices such as SVC, TCSC, STATCOM, UPFC, SSSC, VSC-based Static Phase Shifter (SPS) and Interline Power Flow Controller (IPFC) in power system. It is one of the most popular intelligent technique for solving such a complex problem in terms of improvement of the stability of the transmission system. Norouzi and Sharaf [10] investigated the dynamic performance of the SSSC, theoretically as well as by the digital simulator. This approach shows that the PLL inherent delay, has a great effect on the dynamic operation of the SSSC and a new auxiliary regulator is proposed to enhance its dynamic performance.

The Newton Raphson AC power flow method along with the modeling of TCSC for the transient \& voltage stability improvement is studied and presented in [14]. The effect of STATCOM, SSSC \& UPFC to increase the loadability margin \& enhancement of voltage stability by applying saddle node bifurcation theory with PSAT is investigated in [15]. The simulation program of the transient model \& control system of UPFC for improving the transient behavior and voltage stability margin have appeared in [16].

\section{PROBIEM FORMULATION}

The problems that are to be faced in planning stage are appropriate type, location, size and setting for these controllers for various applications. This project is based on the optimal location problem in the transmission line in a power system. FACTS devices is one of the most common devices used in the transmission line. However, FACTS device has many types and the type has there our model.

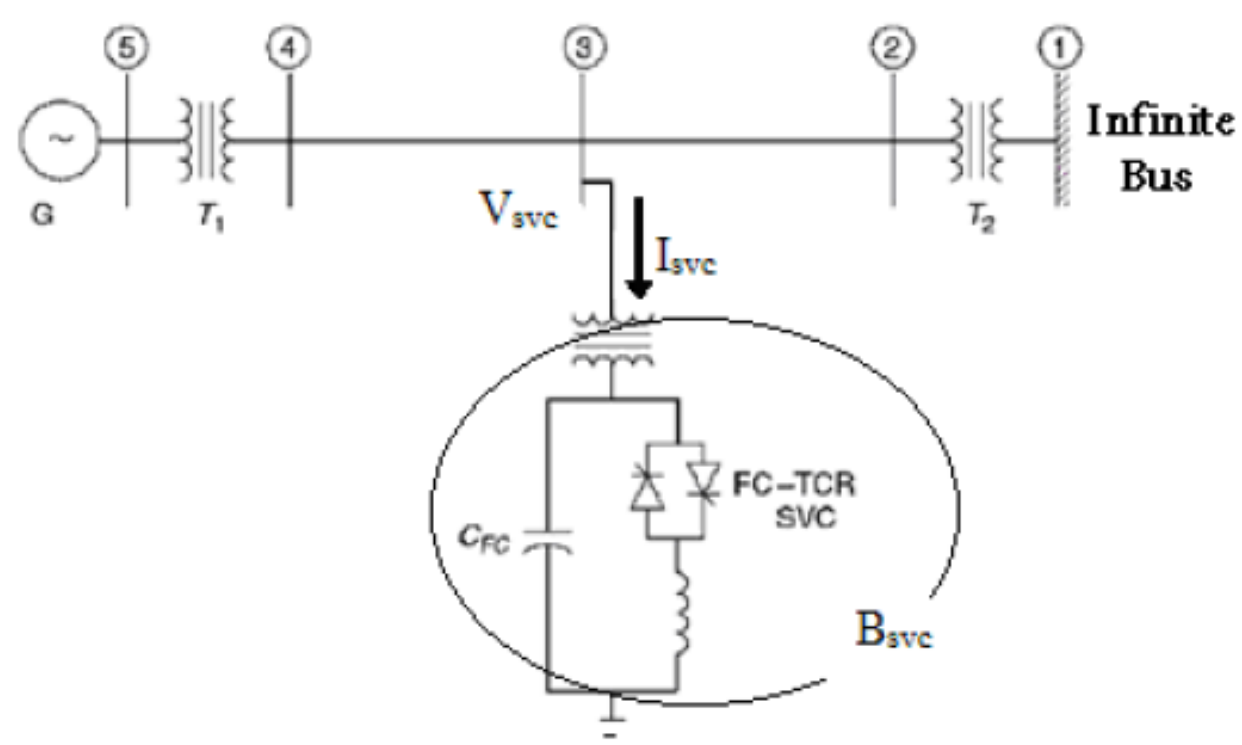

Fig.1: Single Line diagram of SVC connected to an infinite bus 
In this project, we only consider SVC. In the present study, the multiobjective function is formulated to find the optimal location and size of SVC device by minimizing certain objective functions subject to satisfy some network constraints. The SVC is a shunt type FACTS device defined as a shunt connected Static VAR generator or absorber whose output is adjusted to exchange capacitive or inductive current so as to maintain or control specific parameters of the power system,typically bus voltage. As an important component for voltage control, it is usually installed at the receiving node of the transmission lines. In Fig 5.1, the SVC is modelled as a shunt element with a compensated reactive power, $\mathrm{Q}_{\text {svC, }}$ set by available inductive and capacitive susceptances.

From Fig.1, the current drawn and reactive power injected by the SVC can be expressed as:

$$
\begin{aligned}
& \mathrm{I}_{\mathrm{svc}}=\mathrm{jB}_{\mathrm{svc}} \times \mathrm{V} \\
& \mathrm{Q}_{\mathrm{svc}}=-\mathrm{jB}_{\mathrm{svc}} \times \mathrm{V}^{2} \\
& \mathrm{~B}_{\mathrm{svc}(\min )} \leq \mathrm{B}_{\mathrm{svc}} \leq \mathrm{B}_{\mathrm{svc}(\max )}
\end{aligned}
$$

Where $\mathrm{B}_{\mathrm{SVC}}, \mathrm{I}_{\mathrm{SVC}}$ and $\mathrm{Q}_{\mathrm{SVC}}$ are the susceptance, injected current and injected reactive power of SVC, respectively.

\section{$>$ Objective Function}

Voltage stability is an important problem of electric power system. A multi-objective function is considered to find out a solution consisting of both the SVC location and size that minimizes the voltage deviation, total power loss and installation cost described as follows:

\section{- Minimize the Active Power Loss:}

The total power loss in an electric power system is given by,

$$
\mathrm{P}_{\text {loss }}=\sum_{\mathrm{l}=1}^{\mathrm{b}} \mathrm{R}_{1} \mathrm{I}_{1}^{2}=\sum_{\mathrm{i}=1}^{\mathrm{n}} \sum_{\mathrm{j}=1, \mathrm{i}=\mathrm{j}}^{\mathrm{n}}\left[\mathrm{V}_{\mathrm{i}}^{2}+\mathrm{V}_{\mathrm{j}}^{2}-2 \mathrm{~V}_{\mathrm{i}} \mathrm{V}_{\mathrm{j}} \cos \left(\delta_{\mathrm{i}}-\delta_{\mathrm{j}}\right)\right] \mathrm{Y}_{\mathrm{ii}} \cos \varphi_{\mathrm{ij}}
$$

where $\mathrm{b}$ is the number of lines, $\mathrm{R}_{1}$ is the resistance of line $1, \mathrm{I}_{1}$ is the current through line $1, \mathrm{~V}_{\mathrm{i}}$ and $\delta_{\mathrm{i}}$ are the voltage magnitude and angle at node iand $Y_{\mathrm{ij}}$ and $\varphi_{\mathrm{ij}}$ are the magnitude and angle of the line admittance, respectively.

\section{- Minimize the Voltage Deviation:}

The voltage improvement index for a power system is defined as the deviation of voltage magnitudes at each from unity. Thus, for a given system, the voltage improvement index is defined as,

$$
\mathrm{L}_{\mathrm{v}}=\sum_{\mathrm{i}=1}^{\mathrm{n}}\left(\frac{\mathrm{V}_{\text {iref }}-\mathrm{V}_{\mathrm{i}}}{\mathrm{V}_{\text {iref }}}\right)^{2}
$$

where $\mathrm{n}$ is the number of buses, $\mathrm{V}_{\text {iref }}$ is the reference voltage at bus iand $\mathrm{V}_{\mathrm{i}}$ is the actual voltage at bus $i$.

\section{- Minimize the Installation Costs:}

The total SVC cost in US\$/KVar is given as :

$$
\mathrm{C}_{\mathrm{svc}}=0.0003 \mathrm{~S}^{2}-0.3051 \mathrm{~S}+127.38 \quad[\mathrm{US} \$ / \mathrm{KVar}]
$$

$\mathrm{C}_{\mathrm{SVC}}=$ the cost of SVC devices in [US $\$ / \mathrm{KVar}$ ]

$\mathrm{S}=$ Operating range of SVC in [MVar] 
The cost of installation of SVC devices has been mathematically formulated and given by the following equation;

$$
\mathrm{IC}=\mathrm{C}_{\mathrm{svc}} \times \mathrm{S} \times 1000
$$

Where

$\mathrm{IC}=$ the installation cost of SVC device in [US\$]

\section{$>$ Problem Constraints}

As the main reason of applying SVC is to control line real and reactive power flows and bus voltages, the following constraints are considered.

\section{- Power Flow Balance Equations:}

The balance of active and reactive powers must be satisfied at each node. Power balance with respect to a bus can be formulated as:

$$
\begin{aligned}
& \mathrm{P}_{\mathrm{Gi}}-\mathrm{P}_{\mathrm{Li}}=\mathrm{V}_{\mathrm{i}} \sum_{\mathrm{j}=1}^{\mathrm{n}}\left[\mathrm{V}_{\mathrm{j}}\left[\mathrm{G}_{\mathrm{ij}}^{\prime} \cos \left(\delta_{\mathrm{i}}-\delta_{\mathrm{j}}\right)+\mathrm{B}_{\mathrm{ij}}^{\mathrm{i}} \sin \left(\delta_{\mathrm{i}}-\delta_{\mathrm{j}}\right)\right]\right. \\
& \mathrm{Q}_{\mathrm{Gi}}-\mathrm{Q}_{\mathrm{Li}}=\mathrm{V}_{\mathrm{i}} \sum_{\mathrm{j}=1}^{\mathrm{n}}\left[\mathrm{V}_{\mathrm{j}}\left[\mathrm{G}_{\mathrm{ij}}^{\prime} \sin \left(\delta_{\mathrm{i}}-\delta_{\mathrm{j}}\right)+\mathrm{B}_{\mathrm{ij}}^{\prime} \cos \left(\delta_{\mathrm{i}}-\delta_{\mathrm{j}}\right)\right]\right.
\end{aligned}
$$

where, $\mathrm{P}_{\mathrm{Gi}}$ and $\mathrm{Q}_{\mathrm{Gi}}$ are the generated active and reactive powers, and $\mathrm{P}_{\mathrm{Li}}$ and $\mathrm{Q}_{\mathrm{Li}}$ are the load active and reactive powers at node $i$. The conductance, $G^{\prime}{ }_{i j}$ and susceptance, $B{ }^{\prime}{ }_{i j}$ represent the real and imaginary components of element $\mathrm{Y}^{\prime}{ }_{\mathrm{ij}}$ of the $\left[\mathrm{Y}_{\mathrm{bb}}{ }\right]$ matrix, obtained by modifying the initial nodal admittances matrix when introducing the SVC.

\section{- Power Flow Limit:}

The apparent power that is transmitted through a branch 1 must not exceed a limiting value, $S_{1}$ max, which represents the thermal limit of the line or transformer in steady-state operation:

$\mathrm{S}_{1} \leq \mathrm{S}_{\operatorname{lmax}}$

Bus voltage limits:

Bus voltages must be maintained around the nominal value and it is given by:

$\mathrm{V}_{\text {imin }} \leq \mathrm{V}_{\text {inor }} \leq \mathrm{V}_{\text {im }}$

In practice, the accepted deviations can reach up to $10 \%$ of the nominal values.

\section{Fitness Function}

The main aim of this study is to determine the optimal location of SVC in such way that the total power losses of the and the cost of installation are minimized and at the same time system constrains are met. In this condition, the voltage at different buses is kept within acceptable levels.

The fitness function of this problem according to the above mentioned statement is as follow: $\mathrm{FF}: \mathrm{F}(\mathrm{x})=\mathrm{W}_{1} \times \mathrm{V}_{\mathrm{k}}+\mathrm{W}_{2} \times \mathrm{IC}$

In which

$\mathrm{W}_{1}$ and $\mathrm{W}_{2}$ are the weight factors.

$\mathrm{IC}=$ cost of installation of SVC

$\mathrm{V}_{\mathrm{k}}=$ voltage contribution at bus $\mathrm{K}$.

\section{STEP BY STEP ALGORITHM FOR OPTIMAL PLACEMENT OF SVC USING PSO}

Step1:Enter line data and bus data

Step2:Set the loading 
Step3: Run the load flow and determine voltage for all the buses.

Step4: Evaluate Transmission losses before SVC is placed.

Step5: Placement of SVC using voltage nominal value. ( $\mathrm{V}_{\text {imin }} \leq \mathrm{V}_{\text {inor }} \leq \mathrm{V}_{\text {imax }}$ )

Step6: Generate randomly ' $n$ ' number of particles, where each particles represents as particle $[\mathrm{i}]=[\mathrm{bsvc} 1, \mathrm{bsvc} 2$. ..bsvcj], where $\mathrm{j}$ represents number of weak buses.

Step7: Generate the particle velocity V[i] $=0.4 *$ rand $*$ Vmax

Step8: Run the load flows by placing a particle ' $i$ ' at the weak bus for reactive power compensation and store the voltage.

Step9: If the range of voltages lie in the range of .95pu $<\mathrm{v}<1.05 \mathrm{pu}$ then go to next step else go to step13.

Step10: Evaluate the fitness function.

Step11: Determine pbest value and then identify gbest value.

Step12: Update the velocities and position of particle.

Step13: If maximum iteration number is reached, then go to next step else go to step6.

Step14: Evaluate transmission losses after SVC is placed.

Step15: Stop

\section{RESULT}

This result obtained on the performance of power system with the placement of SVC. The installation of SVC, has been studied on the IEEE 14 bus system consists of 14 buses and 20 transmission lines, for their placement at arbitrary location and optimal location decided by PSO. The performance has been studied on 14-bus system, when the loading is 1.6 times of the given base load.

The parameter of the optimization algorithm is identified through trial and error methods are listed below: -

Table.1: Parameter of optimization technique

\begin{tabular}{|c|c|}
\hline Parameters & PSO \\
\hline Population size & 50 \\
\hline Inertial Weight, $w$ & $0.9-0.2$ \\
\hline Constant,C1 & $0-2$ \\
\hline Constant,C2 & $0-2$ \\
\hline Number of iteration & 50 \\
\hline Rand1 & $0-1$ \\
\hline Rand2 & $0-1$ \\
\hline
\end{tabular}

The result obtained with the algorithm has been compared to those calculated by power flow solution. The system was loaded 1.6 times of the given base load. Consequently, all the voltages of the load buses are shown in Table.2. After installation of SVC at different different buses the voltages of weak buses are increased as shown in table Table.2.

The convergence graph of PSO is shown in Figure.2. From the above comparison it is clear that the voltage profile is improved is very much improved, when the SVC is installed at bus no. 11. It can be seen that the graph converges rapidly with number of iteration and attains the minimum value as 0.6381 . At the end of fifty iterations PSO identifies the location of SVC at bus no. $5,9,11,14$. 
Table.2: IEEE-14 Bus System with Voltages and Angles at 1.6 times of the given base load at various Buses

\begin{tabular}{|c|c|c|c|c|c|c|c|c|c|c|}
\hline \multirow{2}{*}{$\begin{array}{l}\text { Bus } \\
\text { No. }\end{array}$} & \multicolumn{2}{|c|}{ Without SVC } & \multicolumn{2}{|c|}{$\begin{array}{c}\text { With SVC at Bus } \\
\text { No. } 5\end{array}$} & \multicolumn{2}{|c|}{$\begin{array}{c}\text { With SVC at Bus } \\
\text { No. } 9\end{array}$} & \multicolumn{2}{|c|}{$\begin{array}{c}\text { With SVC at Bus } \\
\text { No. } 11\end{array}$} & \multicolumn{2}{|c|}{$\begin{array}{c}\text { With SVC at Bus } \\
\text { No. } 14\end{array}$} \\
\hline & Voltage & Angle & Voltage & Angle & Voltage & Angle & Voltage & Angle & Voltage & Angle \\
\hline 1 & 1.045 & 0 & 1.045 & 0 & 1.045 & 0 & 1.045 & 0 & 1.045 & 0 \\
\hline 2 & 1.05 & -0.1692 & 1.05 & -0.1683 & 1.05 & -0.1688 & 1.05 & -0.1691 & 1.05 & -0.169 \\
\hline 3 & 1.055 & -0.398 & 1.055 & -0.3954 & 1.055 & -0.3969 & 1.055 & -0.3977 & 1.055 & -0.3975 \\
\hline 4 & 1.014 & -0.3173 & 1.0225 & -0.3172 & 1.0195 & -0.3182 & 1.0164 & -0.318 & 1.0175 & -0.3181 \\
\hline 5 & 1.0173 & -0.2745 & 1.0309 & -0.2764 & 1.0211 & -0.2743 & 1.0189 & -0.2746 & 1.0196 & -0.2745 \\
\hline 6 & 1.06 & -0.4474 & 1.06 & -0.446 & 1.06 & -0.44 & 1.06 & -0.4445 & 1.06 & -0.4427 \\
\hline 7 & 1.0174 & -0.4066 & 1.0212 & -0.4058 & 1.035 & -0.4082 & 1.0251 & -0.4079 & 1.0285 & -0.4081 \\
\hline 8 & 1.067 & -0.4066 & 1.067 & -0.4058 & 1.067 & -0.4082 & 1.067 & -0.4079 & 1.067 & -0.4081 \\
\hline 9 & 0.9915 & -0.4545 & 0.9952 & -0.4536 & 1.0264 & -0.4551 & 1.0068 & -0.4556 & 1.0135 & -0.4555 \\
\hline 10 & 0.991 & -0.4617 & 0.9941 & -0.4607 & 1.0201 & -0.4607 & 1.0151 & -0.4664 & 1.0094 & -0.4616 \\
\hline 11 & 1.0192 & -0.4578 & 1.0208 & -0.4567 & 1.0341 & -0.4539 & 1.0627 & -0.4724 & 1.0286 & -0.4556 \\
\hline 12 & 1.0321 & -0.4719 & 1.0323 & -0.4704 & 1.0348 & -0.4644 & 1.0333 & -0.4689 & 1.0403 & -0.4688 \\
\hline 13 & 1.0208 & -0.4726 & 1.0214 & -0.4713 & 1.0261 & -0.4662 & 1.0231 & -0.4701 & 1.0362 & -0.4744 \\
\hline 14 & 0.9734 & -0.4936 & 0.9758 & -0.4923 & 0.9962 & -0.4897 & 0.9834 & -0.4924 & 1.0413 & -0.5147 \\
\hline
\end{tabular}

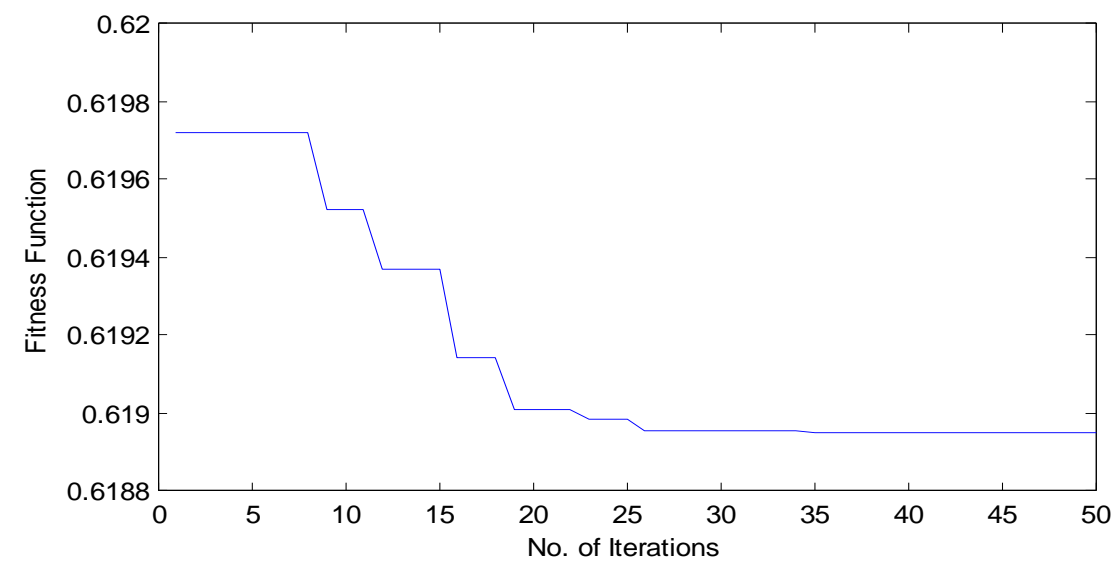

(a) at bus no. 5 


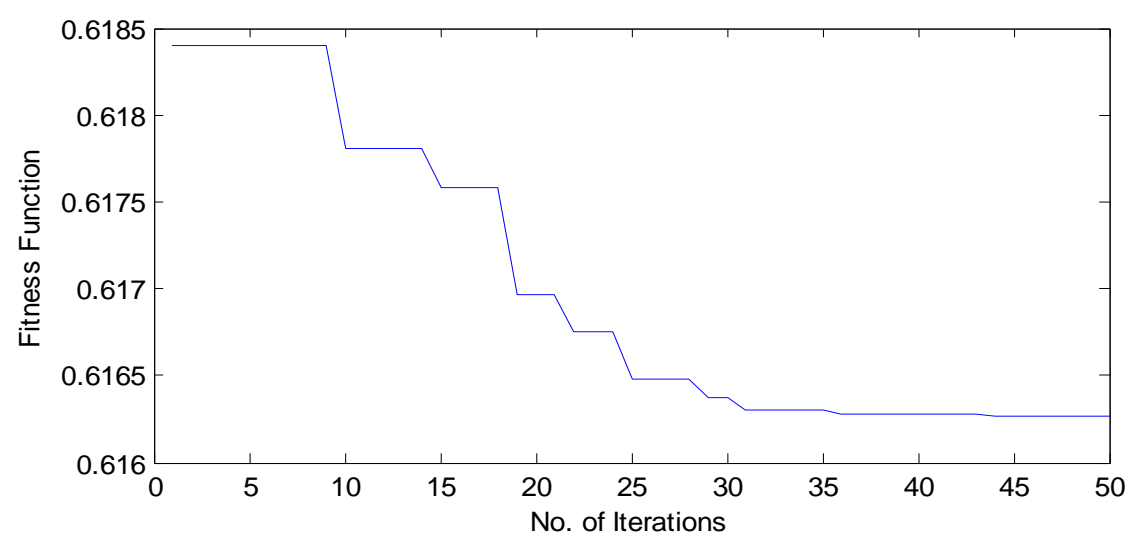

(b) at bus no. 9

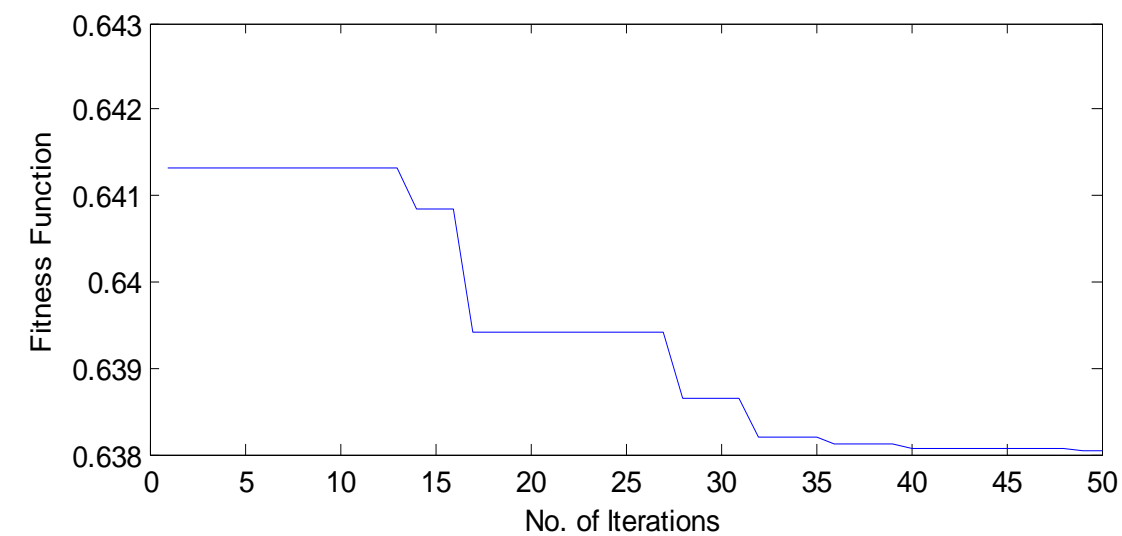

(c) at bus no. 11

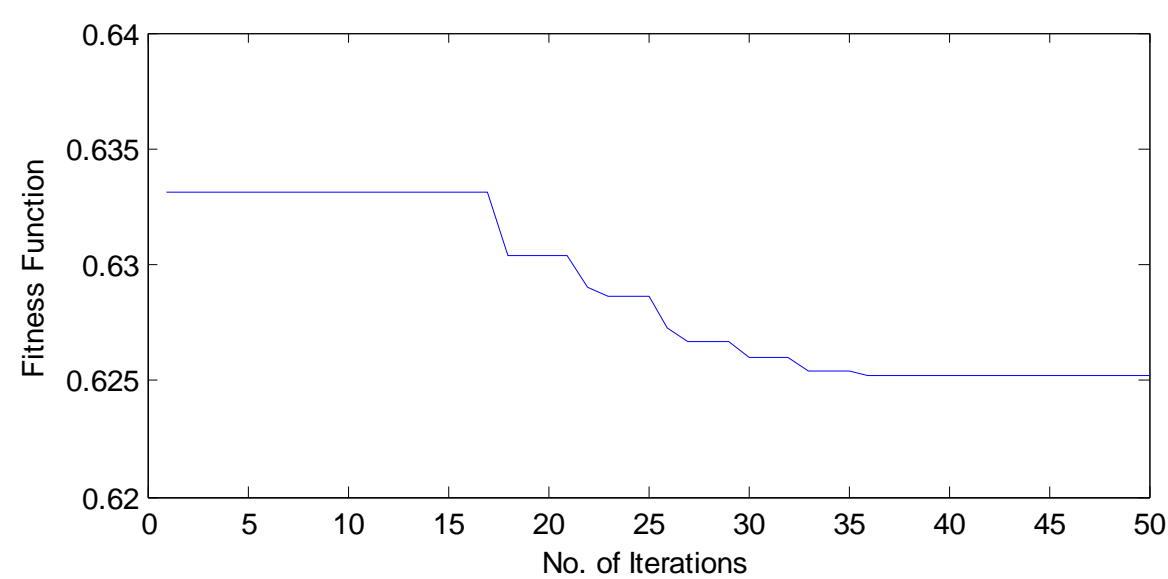

(d) at bus no. 14

Fig. 2: Convergence graph of PSO at various buses for 1.6 times loading

With SVC placed at bus no. 11 the voltage profile at each bus is plotted in Figure. 3 for 1.6 times of given base load. It is observed that the bus voltage profile has been largely enhanced and the maximum deviation occurs at bus no.11. 


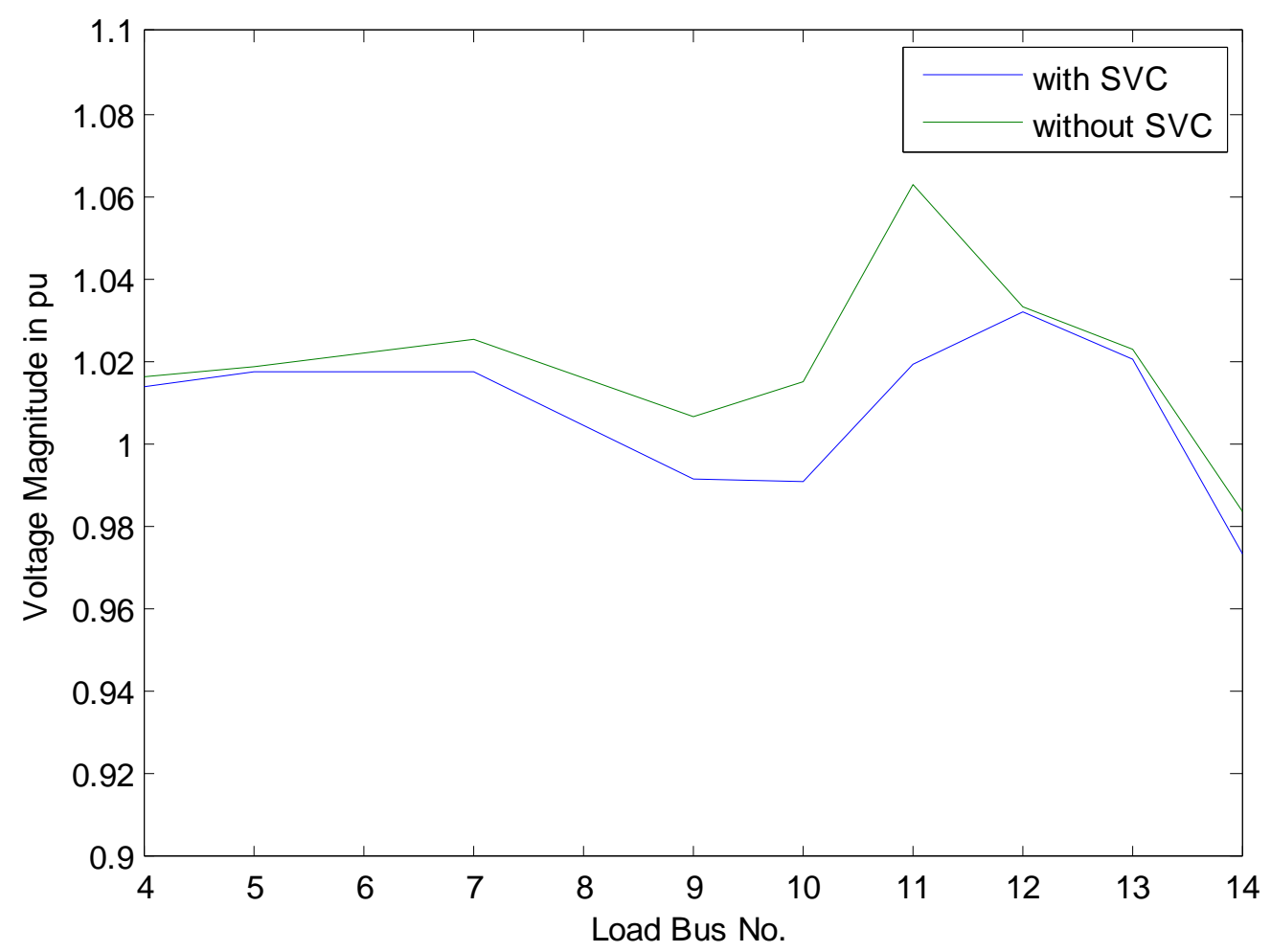

Fig. 3: Voltage Profile in pu for 1.6 times loading without SVC \& with SVC at bus no. 11

\section{CONCLUSION}

The implementation of PSO algorithm to solve the OPF problem is useful and worthofinvestigation. Moreover, PSO algorithm is easy to apply and simple since it has fewernumber of parameters to deal with comparing to other modern optimization algorithms.Inaddition, PSO algorithm is appropriate for optimal dispatch of real power of generatorsOPF has been solved by using PSO and giving theminimum cost for several load cases. At the same test system applying OPF sensitivityanalysis can give an indication to whichof control variables have most effect to adjustviolations of operating constraints.

An OPF method is proposed using PSO algorithm. Small signal stability is taken into account in the OPF by limiting real parts of all eigenvalues to be negative as well as constraining damping ratios of certain interesting oscillation modes above certain level. The method is implemented on a 14-bus IEEE test power system model validated to be able to find optimal (or near-optimal) operating point. Convergence of the OPF process is an issue, which means the OPF sometimes can only find an local optimal point instead of the global optimal point. To use the OPF method more efficiently, some further work should be done in this regard to improve the convergence ability of the method.

\section{REFERENCE}

I. Mehrdad Ahmadi Kamarposhti, and Hamid Lesani, Comparison between Parallels and Series FACTS Devices on Static Voltage Stability Using MLP Index, SPEEDAM 2010, International Symposium on Power Electronics, Electrical Drives, Automation and Motion.

II. M. Ahmadi Kamarposhti, M. Alinezhad, H. Lesani, N. Talebi, “Comparison of SVC, STATCOM, TCSC, and UPFC Controllers for Static Voltage Stability Evaluated by Continuation Power Flow Method," The IEEE 8th Annual Electrical Power \& Energy Conference, Canada, October, 2008, pp. 1-8. 
III. Shankaralingappa C. B., and Suresh. H. Jangamashetti, "FACTS Controllers to Improve Voltage Profile and Enhancement of Line Loadability in EHV Long Transmission Lines" The IEEE 8th Annual Electrical Power \& Energy Conference, Canada, October, 2008, pp. 1-8.

IV. Hiroshi YonezawaMichiharuTsukada John J. Paserba Toshiaki Shimato Katsuhiko Matsuno Gregory F. Reed and Isao Iyoda,"Study of a STATCOM Application for Voltage Stability Evaluated by Dynamic PV Curves and Time Simulations", IEEE PESW-2000 vol. 2.

V. T. Hiyamat, H. Kiharat, H. Miyauchit, and T. H. OrtmeyerJ, "Fuzzy logic switching of FACTS Devices for stability enhancement", ISCAS,IEEE, 1996 vol. 1.

VI. Salim. Haddad, A. Haddouche, and H. Bouyeda ,"The use of Facts devices in disturbed Power Systems-Modeling, Interface, and Case Study", International Journal of Computer and Electrical Engineering, Vol. 1, No. 1, April 2009.

VII. Rakibuzzaman Shah, Nadarajah Mithulananathan, Ramesh Bansal,Kwang Y. Lee and Abraham Lomi, "Influence of Large-scale PV on Voltage Stability of Subtransmission System", International Journal on Electrical Engineering and Informatics - Volume 4, Number 1, March 2012.

VIII. Garng. M. Huang, and Nirmal-Kumar C Nair, "Incorporating TCSC into the Voltage Stability Constrained OPF Formulation", Proc. IEEE PES Summer Meeting, July 2001, Canada.

IX. Kwang Y. Lee,Malihe M. Farsangi, and Hossein Nezamabadi-pour, "Hybrid of Analytical and Heuristic Techniques for FACTS Devices in Transmission Systems", IEEE PES 2007, pp. 1-8.

X. Amir H. Norouzi, A. M. Sharaf, "Two Control Schemes to Enhance the Dynamic Performance of the STATCOM and SSSC", IEEE Transactions on Power delivery, vol. 20, no. 1, January 2005.

XI. N.K.Sharma and P.P.Jagtap, "Modelling and application of Unified Power Flow Controller (UPFC)", Third International Conference on Emerging Trends in Engineering and Technology, ICETET,IEEE 2010.

XII. H. F. Wang, M. Jazaeri, and Y. J. Cao, "Analysis of Control Conflict between UPFC Multiple Control Functions and Their Interaction Indicator", International Journal of Control, Automation, and Systems, vol. 3, no., pp. 315-321, June 2005.

XIII. H.Chen, Y.Wang and R.Zhou, "Transient and voltage stability enhancement via coordinated excitation and UPFC control", IEE Proc.- Gener.. Transm. I)istrib., Vol. 148, Na 3, May 2001.

XIV. Abdel Moamen, M. A Narayana Prasad Padhy, "Newton-Raphson TCSC Model for Power Flow Solution of Practical Power Networks”, PESS, IEEE,2002, vol.3, pp. 1488-1493.

XV. R. Natesan and G. Radman, "Effects of STATCOM, SSSC and UPFC on Voltage Stability" SSST IEEE 2004 pp.546-550.

XVI. S.H. Hosseini and A. Ajami, "Voltage Regulation and Transient Stability Enhancement of a Radial AC Transmission System Using UPFC" The 30th Annual Conference of the IEEE Industrial Electronics Society, November 2 - 6,2004, Busan, Korea. 